\section{How heuristics and cognitive biases affect vaccination decisions}

\author{
Como as heurísticas e os vieses cognitivos \\ afetam as decisões sobre vacinação
}

\section{Cómo los sesgos heurísticos y cognitivos afectan a las decisiones de vacunación}

Paula Mendes Luz 1 Paulo Nadanovsky ${ }^{2}$ Julie Leask 3

\begin{abstract}
Immunization, the most successful public health intervention to date, can only be effective if eligible individuals or their legal representatives have access to vaccines and subsequently comply with their use. Under-vaccination stems from multiple causes: access, affordability, awareness, acceptance and activation. In this paper, we focus on acceptance and, specifically, on factors pertaining to individual or parental compliance, specifically the psychology of judgment and decision making. We describe how heuristics and cognitive biases - a facet of thoughts and feelings - affect vaccination decision making. Additionally, we address when and how social processes play a role and how attitudes towards vaccines might reflect a more general underlying attitude or ideology. The understanding of how decision making, with regards to vaccines occurs, and the role played by heuristics and cognitive biases can help inform more appropriate public health interventions.
\end{abstract}

Vaccination; Cognition; Heuristics

\author{
Correspondence \\ P. M. Luz \\ Instituto de Pesquisa Clínica Evandro Chagas, Fundação \\ Oswaldo Cruz. \\ Av. Brasil 4365, Rio de Janeiro, RJ 21040-360, Brasil. \\ paula.luz@ini.fiocruz.br \\ ${ }_{1}^{1}$ Instituto de Pesquisa Clínica Evandro Chagas, Fundação \\ Oswaldo Cruz, Rio de Janeiro, Brasil. \\ 2 Instituto de Medicina Social, Universidade do Estado do Rio de \\ Janeiro, Rio de Janeiro, Brasil. \\ ${ }^{3}$ Faculty of Medicine and Health, University of Sydney, Sydney, \\ Australia.
}




\section{Introduction}

Immunization, the most successful public health intervention to date, can only be effective if eligible individuals or their legal representatives have access to vaccines and subsequently comply with their use. Under-vaccination in a particular location might result from multiple causes, grouped into the "5As": Access, Affordability, Awareness, Acceptance and Activation 1, which interact at layered levels with policies, institutions, communities, and inter- and intra-personal factors 2,3 . In this paper, we focus on factors pertaining to individual or parental compliance, i.e., we assume access, affordability and awareness. Specifically, we focus on the psychology of judgment and decision making, and behavioral economics 4 . The incorporation of psychological insights to increase vaccine coverage was reviewed in a 2017 paper by Brewer et al. 5 , describing how thoughts and feelings and social processes inform decision making. Here, we focus specifically on how heuristics and cognitive biases - a facet of thoughts and feelings - affect vaccination decision making.

Studies have shown how people adopt simple heuristics when faced with a complex, probabilistic task. A heuristic is a mental shortcut that allows people to solve problems and make judgments quickly and intuitively. Sometimes referred to as rule-of-thumb strategies, heuristics significantly shorten decision-making time and allow people to function more efficiently without constantly stopping to carefully think about their next course of action 6 . Heuristics are helpful in many situations, but they can also lead to predictable biases (or systematic errors) when making predictions. The pioneers in the field of judgment and decision making include Sarah Lichtenstein, Paul Slovic and Amos Tversky, who later collaborated with Daniel Kahneman 6,7.

Using the terminology popularized by Kahneman's Thinking, Fast and Slow 6 (p. 21), humans' two modes of thinking are fast (system 1), which "operates automatically and quickly with no sense of voluntary control", and slow (system 2), which "requires attention to the effortful mental activities that demand it and is associated with the subjective experience of agency and choice". Decision-making results from both systems and is called dual processing.

As proposed in theoretical models of behavior, such as the Health Belief Model, most applied in studies of immunizations, an individual's perception of disease risk and severity as well as the perceptions of benefits and barriers of vaccines are thought to influence behavior. In dual processing, this would be a system 2 evaluation, weighing-up the probability of outcomes related to disease and vaccine according to the best available evidence. However, as described shortly, when deciding on vaccinating oneself or a child, a system 1 perception of risk likely plays a major role. In this paper, we focus on the heuristics and cognitive biases that have been linked and most described and studied concerning vaccination decisions. The understanding of how decision making regarding vaccines occurs and the role played by heuristics and cognitive biases can help inform more appropriate public health interventions.

\section{Heuristics and biases relevant to the receiver and to the message}

Risk percep tions refer to an individual's intuitive assessment of risk, which is mostly informed by whatever knowledge and information one may receive from multiple sources 7 . The Internet is increasingly becoming the source of health-related information where expert-knowledge information can be found in addition to narratives containing personal information of unknown validity. Compared to objective risk estimates, narratives provide information on an individual's experience which may evoke an emotional response (affect) guiding risk judgment beyond objective information. This has been termed "affect heuristics" 8,9. In an online experimental study conducted with German college students, participants were provided with statistical information and narratives detailing personal experiences with a disease along with the recommendation to vaccinate their child against the disease 10 . The objective was to evaluate if the emotional tone of the narrative would influence the perceived magnitude of the risk and subsequent vaccine intention. Participants were exposed to information that was manipulated regarding the number of narratives cited as well as their emotional content. Following, they were asked to assess disease risk and severity as well as report on vaccine intentions. Authors found that the number of narratives, as opposed to the objective statistical infor- 
mation, was the critical variable influencing the judgments made about the risk of adverse events following vaccination and thus decreasing vaccination intentions 10 .

Another 2015 study explored the impact of "affect heuristic" in a dual processing framework for decision making regarding a hypothetical avian influenza vaccine scenario on a nationally representative sample from the United States 11 . The study specifically assessed the direction of influence between heuristic and systematic processing variables by fitting alternative models to empirical data. Vaccine intention was measured by asking how likely participants would be to get the new vaccine assuming it was readily available and free. Benefits and risks of vaccination were both assessed with one item each, similarly to susceptibility and severity perception regarding the hypothetical avian influenza. Affect was measured by asking participants to indicate "their feeling toward getting vaccinated". The results suggested a bidirectional influence between affect and beliefs: individuals with more positive affect considered vaccines to be more beneficial and perceived themselves more susceptible; affect also had a direct positive effect on vaccine intention. Moreover, the results indicated that perceived severity predicted affect.

The "availability heuristic" is the mental shortcut that relies on immediate examples that come to mind when evaluating how risky an outcome is 8 . That is, individuals rate a hazard as riskier when it has a more memorable but less probable outcome than a hazard with a less memorable but more probable outcome. For example, meningococcal disease is a rare disease that the public can link to vivid images of victims with meningococcal rash and amputated limbs. Influenza, on the other hand, is both more common and more transmissible but seen as less risky due to the banal unremarkable nature of the outcomes: upper respiratory symptoms. Relatedly, people may overestimate the probability of diseases that have increased case-fatality rates without considering attack rates/incidence, leading to frightening scenarios of severe disease.

"Ambiguity aversion" is the displayed preference for known or certain probabilities over unknown or uncertain probabilities 8 . It was found to play a role in a qualitative study using semi-structured indepth interviews with Australian parents, divided into groups depending on the vaccine status of their child (complete, incomplete, partial and none) 12. Dread of the unknown stood out: both vaccinators and non-vaccinators dreaded the unknown but perceived the unknown differently. Among vaccinators, diseases that parents were least familiar with were perceived as more severe and therefore worth preventing (e.g., meningitis). In contrast, non-vaccinators dreaded the unknown from vaccines which were described as not only ineffective but also dangerous. Meanwhile, the disease was perceived as risky only for children "with poor nutrition, poor sanitation, and compromised immune system", and was also minimized given that "access to hospital were readily if needed" 12 (p. 7).

The "optimism bias", cited as one of the most consistent and prevalent biases though absent in depressed individuals 13 , relates to our inferences about the probability of future events and is marked by an overestimation of the probability of positive things or an underestimation of the probability of negative things happening to oneself. In the study cited above among Australian parents, when evaluating a hypothetical news about a new strain of influenza, optimism bias was shown to play a role 12 . Though scenarios were constructed to include the interviewed in the at-risk group, participants did not believe that they were at risk. Notably, they were more willing to take risks by not vaccinating when reacting to a scenario that implied risks for them (parents) than their children.

"Anticipated regret" (or regret aversion) appears frequently in studies as an influencer on vaccination decisions. Here, individuals anticipate regret of a particular outcome from vaccinating or not vaccinating. It elicits a strong negative emotion. A 2016 meta-analysis on the role of anticipated regret on multiple types of health behavior showed it to be associated with behavioral intention as well as actual behavior engagement. Moreover, anticipated regret from a decision to engage with a behavior (action regret) was less of a determinant of behavior than anticipated regret from inaction (i.e. from deciding not to engage with a behavior) 14 . This was particularly relevant for vaccination; in nine out of ten studies ratings of anticipated regret from action (vaccination) were lower than ratings of inaction regret (foregoing vaccination). As stated by authors, "inaction often defies medical authority, thereby leaving the decision maker more vulnerable to self-blame" 14 (p. 1270), making anticipated inaction regret an important psychological driver of vaccine uptake. Similarly, in a study of 114 parents, authors explored the impact of disease and vaccine perceptions of risks, the benefits of vaccines alongside the perception of anticipated regret from vaccinating or not, and the feelings of responsibility if harm 
occurred as a result of inaction (omission) or action (commission) 15. Anticipated regret of harm occurring as a result of not immunizing was highly correlated with the likelihood of opting for MMR vaccine (explaining 24\% of the variance), while anticipated regret of harm occurring as a result of immunizing with MMR was highly correlated with the likelihood of immunizing with single vaccines (measles, mumps, rubella).

A contrasting (and controversial) related bias is "omission bias" or the tendency to prefer harm due to an act of omission over an act of commission. Omission bias was suggested to play a role in a study that found that parents were willing to accept significantly worse outcomes from influenza disease than from its vaccine 16 . One rationale for this finding could stem from the fact that vaccines are administered as preventive to healthy individuals, and thus their benefits can only be estimated at the population level, while their risks (real or alleged) are visible at the individual level 17 . That said, others authors have suggested that omission bias actually operates via the anticipation of regret, which is hence the primary cognition for making vaccination decisions 18 .

"Confirmation bias" relates to the observation that "strong initial views are resistant to change because they influence the way that subsequent information is interpreted" 7 (p. 281). The ease with which health information may be searched online brings the potential for confirmation bias to play an everincreasing role in the realm of vaccination as well as other health decisions. Importantly, the internet has shifted the frequency of medical or scientific information relative to unsourced information on a topic, becoming a platform for the sharing of stories and/or non-official information 19. In an online experiment, authors showed how health literacy plays a role within the context of confirmation bias 19. A sample of 480 parents of children aged 0 to 4 years were assessed with instruments for measuring health literacy and vaccination beliefs, were exposed to a list with 10 headers of messages about vaccination and were asked to select the 5 which interested them the most. Lastly, they were exposed to two full text messages of approximately 200 words and asked to rate information's perceived credibility and usefulness. As expected from confirmation bias, results showed that parents preferred the headers of messages that were consistent with their beliefs and rated the information that was consistent with their belief as more credible and useful 19.

The "framing effect" is a cognitive bias where choices are influenced by how message content is presented, i.e., if with positive or negative consequences or, as more traditionally described, in a gain- vs. loss-frame. In the initial experiment published in 1984, hypothetical equivalent strategies aimed to counter the "Asian disease" were presented 20 . For each scenario, all of which had exactly the same utility of 200 people being saved, two strategies were presented. In scenario 1 (gain-framed), the strategies were: (A) Saves 200 people vs. (B) Has one-third chance to save 600 people. In scenario 2 (loss-framed), the strategies were: (A) Allows 400 people to die vs. (B) Has a one-third chance that no one would die. The results showed that in scenario 1 people preferred the certain scenario $A$ and in scenario 2 people preferred the uncertain scenario B, that is, the choice of strategy was a function of whether the strategy was presented in a positive or negative frame.

From this original study, multiple empirical studies have explored which type of frame is more effective and in which circumstances. A 2016 study provides an extensive review of the experimental and meta-analytic evidence for the effect of message framing while also challenging the underlying theoretical foundation for the proposed effect 21. A 2018 review of the literature 22 on gain- vs. lossframed messages relating to vaccines included 34 studies (16 of which had already been reviewed in a previous meta-analytic review 23 plus 16 new studies), with 12 showing no significant main or interactive effects of framing on vaccine uptake, intention or attitude. Four studies showed (contrary to initial hypothesis) an effect of loss-framed messages compared to gain-framed. It seems that the relative effectiveness of gain- vs. loss-framed messages depends on other characteristics, pertaining to the individual or to the format and content of the messages. Furthermore, the result of the previous meta-analytic study 23 aligns with these newer findings as it showed that gain- vs. loss-framed messages do not significantly differ in their effectiveness.

Another important bias that has been less studied with regards to vaccines is the "DunningKrueger effect", in which "individuals who lack expertise fail to accurately appraise their own knowledge vis-a-vis experts on the subject” 24 (p. 275). Importantly, individuals generally lack information or are misinformed about the safety of vaccines 25 , while online/social media platforms are used to disseminate information with no scientific evidence 26,27 and/or conspiracy theories (for a validated 
scale to measure conspiracy theories relating to vaccine see Shapiro et al. 28). A 2018 US nationally represented survey evaluated the role of the "Dunning-Krueger effect" on explaining anti-vaccine policy attitudes 24 . Authors measured participant's knowledge about the causes of autism, their belief in the myth that vaccines cause autism, their level of confidence in their knowledge as compared to "medical doctors" or "scientists", and how much they endorsed "anti-vaccination policies" defined as a "how much parents should be able to decide NOT to vaccinate their child" 24 (p. 277). Authors found that individuals who knew less about the causes of autism and who endorsed the myth that vaccines cause autism believed they knew more than medical doctors about the causes of autism, and this overconfidence further correlated with endorsement of policies defined as "anti-vaccination" by authors 24 .

\section{Moral Foundation Theory}

More recently, studies based on the Moral Foundation Theory have provided interesting insights into the study of judgement and decision making towards vaccines. Moral Foundation Theory arises from the field of social psychology and the work of Jonathan Haidt, Jesse Graham, Craig Joseph and others 29,30 and is built upon the idea of moral intuitions and of morality as derived from affect. Of relevance to the present, work by Joshua Greene explains moral judgment within the dual process theory, being determined by both automatic emotional responses and conscious careful reasoning 31,32. Importantly, work generated within Moral Foundation Theory suggests understanding heuristics and cognitive biases as having underlying roots in moral judgement. Historically, individuals endorsing anti-vaccination activities have always existed, likely being a worldwide phenomenon that will not cease to exist 33 . In as much, anti-vaccination may be one manifestation of a deeper set of shared values.

Moral Foundation Theory has been used to understand political ideology 34 with recent studies exploring the role of political orientation in shaping vaccination attitudes. A 2014 survey of over 2,000 demographically diverse individuals from the United States found that those who held a negative attitude towards vaccines, which were by far the minority, did not belong to a specific political group ${ }^{35}$. In contrast, in one online survey conducted in the United States, liberals were found to support pro-vaccine statements more, and anti-vaccine statements less than moderates or conservatives 36. Relatedly, an ecological study observed, at the state level, that states with greater Republican affiliation (compared to Democratic affiliation as per 2012 US election) had significantly lower coverage of routine adolescent vaccines (human papillomavirus, tetanus-diphtheria-acellular pertussis and meningococcal vaccines). Importantly, as highlighted in Motta et al. 24 and clearly explained in Sapolsky ${ }^{37}$, political orientation is one manifestation of broader, underlying ideology that arises from deep, implicit factors and have little to do with a specific political issue. To cite one specific realm, affective differences exist depending on political ideology with studies showing that, on average, conservatives are more anxious by ambiguity, dislike novelty, prefer predictability and structure and perceive circumstances as threatening more readily 37 . One remarkable study showed how unconscious the choosing of politicians can be as children aged 5-13 years elected as "captain of their boat" the winning politician from a pair of faces of elections unknown to them $71 \%$ of the time 38 .

In a 2019 survey, Rossen et al. 39 explored the relationship between negative vaccination attitudes and moral preferences among Australian parents. Using the Moral Foundation Theory as a basis for their study, authors identified which moral foundations were most strongly endorsed by the three different profiles of parents (accepters, fence-sitters, rejecters) using latent profile analysis. Authors found that the moral domains of purity and economic and lifestyle liberty were more strongly endorsed by rejectors of vaccines. Notably, in this Australian sample, though differences were found for three moral foundations as cited above, political ideology was not associated with anti-vaccination profiles, also found in other work from the United States 35.

Another interesting theory proposes that the drivers of anti-vaccination attitudes are not vaccines per se or proximal factors related to it such as its risks and benefits but rather underlying "attitude roots" 40 . Attitude roots has recently been proposed to explain a more general rejection of science, be it related to vaccines, climate or other fields 41 . For vaccines, attitude roots suggest that individuals have emotional or intuitive attitudes towards vaccines and that this attitude motivates them to search 
and accept/reject evidence according to how well it supports their previous attitudes through "motivated reasoning". As such, similar to the "Dunning-Krueger effect" described above, a biased cognitive process is at play whereby individuals first develop an attitude and later selectively search and reason the evidence to support it (instead of going from evidence to attitude) 42. The proposals for this theory suggest that the relevant question to ask is not "why people reject evidence about vaccines" but instead "why do people want to reject the evidence" 40 (p. 2). This shift in perspective suggests that the real reasons for the rejection of vaccines are underlying fears, identity issues and worldviews.

An online survey in 24 countries 40 measured attitudes towards vaccines in addition to the proposed underlying "attitude roots": conspiratorial beliefs, disgust sensitivity toward blood and injections, reactance (i.e. how skeptical an individual is of consensus views and how intolerant they are of people telling them how to think), and individualistic/hierarchical worldviews. Authors found that the conspiratorial beliefs were the strongest predictors of anti-vaccination beliefs in addition to, in order, reactance and disgust sensitivity (even after adjusting for age, gender, education and political ideology). Qualitative studies with non-vaccinating parents have found alignment with intensive parenting practices, beliefs about personal responsibility, self-trust and natural health 43,44 . They may also see themselves set apart, more vigilant and more careful than the "unhealthy others" 45.

\section{Conclusions}

We have highlighted how heuristics and cognitive biases influence an individual's decision; when and how social processes play a role; and how attitudes towards vaccines might reflect a more general underlying attitude or worldview. These findings may help design interventions that will be cognisant of these influencers. Equally, it is important to highlight, as Nesse does, that "emotions are specialized states that adjust physiology, cognition, subjective experience, facial expressions, and behavior in ways that increase the ability to meet the adaptive challenges of situations that have recurred over the evolutionary history of a species" 46 (p. 54). As such, being influenced by emotions per se is not necessarily good or bad. What needs to be established in different contexts is, for example, whether a negative emotion towards a vaccine is an excessive response 46 towards the very small risk (much smaller than the potential benefits) or a prudent skepticism towards a proposed intervention that is given to a healthy individual for a disease the person may never have seen.

We have reviewed some of the studies on heuristics and cognitive biases that have played a role in decision-making regarding vaccination but have by no means been exhaustive. A 2015 critical review evaluated 213 original peer-reviewed, empirical studies on heuristics and cognitive biases relating to patient and/or provider decision making with $28 \%$ of the studies evaluating a decision related to screening or vaccination ${ }^{8}$. Importantly, in the latter, over three-quarters of the studies were based on completely hypothetical decision scenarios, highlighting the need to expand the study of heuristics and biases to real-life scenarios. As for the theoretical foundation for understanding vaccine refusal, we concur with the need to update theoretical models of health behavior 47 in light of the work cited. A 2019 selective review takes a similar approach, highlighting how the knowledge of how people make decisions can better inform strategies that encourage health-behavior change 48 .

As discussed in Pinker's most recent book 49, Enlightenment Now: The Case for Reason, Science, Humanism, and Progress, progress unfolds slowly and incrementally. Vaccines, a remarkable scientific progress, have brought huge achievements in disease control 50, but prevented diseases do not make the news media. Indeed, immunization brings substantial benefits to the population, but, to each participating individual the probability of benefit is usually low (The Prevention Paradox 51 ); and overtime, risk-benefit ratios narrow with disease reduction continuing but vaccine risk (albeit small) remaining constant. We, humans, clearly understand our physical limitations and consequently devise means of achieving our goals by working around the limitations. If we understand our cognitive limitations, our heuristics and their consequent biases, and how our beliefs and attitudes towards vaccines might be influenced by emotions, moral foundations or group alignments, we can better devise means of working around these to achieve our common goals. 


\section{Contributors}

P. M. Luz contributed to the study conception and development, literature review, manuscript writing and review. P. Nadanovsky contributed to the study development, literature review and manuscript writing and review. J. Leask contributed to the study conception, development and guidance, literature review, manuscript writing and review.

\section{Additional informations}

ORCID: Paula Mendes Luz (0000-0001-9746719X); Paulo Nadanovsky (0000-0003-3345-9873); Julie Leask (0000-0001-5095-1443).

\section{Acknowledgments}

To Brazilian National Research Council (CNPq) for the financial support.

\section{References}

1. Thomson A, Robinson K, Vallee-Tourangeau G. The 5As: a practical taxonomy for the determinants of vaccine uptake. Vaccine 2016; 34:1018-24.

2. Bedford H, Attwell K, Danchin M, Marshall H, Corben P, Leask J. Vaccine hesitancy, refusal and access barriers: the need for clarity in terminology. Vaccine 2018; 36:6556-8.

3. McLeroy KR, Bibeau D, Steckler A, Glanz K. An ecological perspective on health promotion programs. Health Educ Q 1988; 15:351-77.

4. Ariely D. Predictably irrational: the hidden forces that shape our decisions. New York: Harper; 2008.

5. Brewer NT, Chapman GB, Rothman AJ, Leask J, Kempe A. Increasing vaccination: putting psychological science into action. Psychol Sci Public Interest 2017; 18:149-207.

6. Kahneman D. Thinking, fast and slow. New York: Farrar, Straus and Giroux; 2011.

7. Slovic P. Perception of risk. Science 1987; 236:280-5.

8. Blumenthal-Barby JS, Krieger H. Cognitive biases and heuristics in medical decision making: a critical review using a systematic search strategy. Med Decis Making 2015; 35:539-57.

9. Slovic P, Finucane ML, Peters E, MacGregor DG. Risk as analysis and risk as feelings: some thoughts about affect, reason, risk, and rationality. Risk Anal 2004; 24:311-22.

10. Betsch C, Ulshofer C, Renkewitz F, Betsch T. The influence of narrative $\mathrm{v}$. statistical information on perceiving vaccination risks. Med Decis Making 2011; 31:742-53.

11. Chen NT. Predicting vaccination intention and benefit and risk perceptions: the incorporation of affect, trust, and television influence in a dual-mode model. Risk Anal 2015; 35:1268-80.

12. Bond L, Nolan T. Making sense of perceptions of risk of diseases and vaccinations: a qualitative study combining models of health beliefs, decision-making and risk perception. BMC Public Health 2011; 11:943.

13. Sharot T. The optimism bias. Curr Biol 2011; 21:R941-5.

14. Brewer NT, DeFrank JT, Gilkey MB. Anticipated regret and health behavior: a meta-analysis. Health Psychol 2016; 35:1264-75.

15. Wroe AL, Bhan A, Salkovskis P, Bedford H. Feeling bad about immunising our children. Vaccine 2005; 23:1428-33.

16. Brown KF, Kroll JS, Hudson MJ, Ramsay M, Green J, Vincent CA, et al. Omission bias and vaccine rejection by parents of healthy children: implications for the influenza A/ H1N1 vaccination programme. Vaccine 2010; 28:4181-5.

17. Dube E, Laberge C, Guay M, Bramadat P, Roy R, Bettinger J. Vaccine hesitancy: an overview. Hum Vaccin Immunother 2013; 9:1763-73.

18. Connolly T, Reb J. Omission bias in vaccination decisions: where's the "omission"? Where's the "bias"? Organ Behav Hum Decis Process 2003; 91:186-202. 
19. Meppelink CS, Smit EG, Fransen ML, Diviani N. "I was right about vaccination": confirmation bias and health literacy in online health information seeking. J Health Commun 2019; 24:129-40.

20. Kahneman D, Tversky A. Choices, values and frames. Am Psychol 1984; 39:341-50.

21. Van 't Riet J, Cox AD, Cox D, Zimet GD, De Bruijn GJ, Van den Putte B, et al. Does perceived risk influence the effects of message framing? Revisiting the link between prospect theory and message framing. Health Psychol Rev 2016; 10:447-59.

22. Penta MA, Baban A. Message framing in vaccine communication: a systematic review of published literature. Health Commun 2018; 33:299-314.

23. O'Keefe DJ, Nan X. The relative persuasiveness of gain- and loss-framed messages for promoting vaccination: a meta-analytic review. Health Commun 2012; 27:776-83.

24. Motta M, Callaghan T, Sylvester S. Knowing less but presuming more: Dunning-Kruger effects and the endorsement of anti-vaccine policy attitudes. Soc Sci Med 2018; 211:274-81.

25. Brown KF, Kroll JS, Hudson MJ, Ramsay M, Green J, Long SJ, et al. Factors underlying parental decisions about combination childhood vaccinations including MMR: a systematic review. Vaccine 2010; 28:4235-48.

26. Kata A. Anti-vaccine activists, Web 2.0, and the postmodern paradigm: an overview of tactics and tropes used online by the anti-vaccination movement. Vaccine 2012; 30:3778-89.

27. Davies P, Chapman S, Leask J. Antivaccination activists on the world wide web. Arch Dis Child 2002; 87:22-5.

28. Shapiro GK, Holding A, Perez S, Amsel R, Rosberger $Z$. Validation of the vaccine conspiracy beliefs scale. Papillomavirus Res 2016; 2:16772.

29. Haidt J. The new synthesis in moral psychology. Science 2007; 316:998-1002.

30. Graham J, Nosek BA, Haidt J, Iyer R, Koleva S, Ditto PH. Mapping the moral domain. J Pers Soc Psychol 2011; 101:366-85.

31. Greene J, Haidt J. How (and where) does moral judgment work? Trends Cogn Sci 2002; 6:51723.

32. Greene JD. Moral tribes: emotion, reason, and the gap between us and them. New York: Penguin Press; 2013.

33. Leask J. Should we do battle with antivaccination activists? Public Health Res Pract 2015; 25:e2521515.

34. Graham J, Haidt J, Nosek BA. Liberals and conservatives rely on different sets of moral foundations. J Pers Soc Psychol 2009; 96:102946.

35. Kahan DM. Vaccine risk perceptions and ad hoc risk communication: an empirical assessment. CCP Risk Perception Studies Report n. 17; Yale Law \& Economics Research Paper n.
491. SSRN 2014; 29 jan. https://ssrn.com/abstract $=2386034$.

36. Rabinowitz M, Latella L, Stern C, Jost JT. Beliefs about childhood vaccination in the United States: political ideology, false consensus, and the illusion of uniqueness. PLoS One 2016; 11:e0158382.

37. Sapolsky RM. Behave: the biology of humans at our best and worst. New York: Penguin Press; 2017.

38. Antonakis J, Dalgas O. Predicting elections: child's play! Science 2009; 323:1183.

39. Rossen I, Hurlstone MJ, Dunlop PD, Lawrence C. Accepters, fence sitters, or rejecters: moral profiles of vaccination attitudes. Soc Sci Med 2019; 224:23-7.

40. Hornsey MJ, Harris EA, Fielding KS. The psychological roots of anti-vaccination attitudes: a 24-nation investigation. Health Psychol 2018; 37:307-15.

41. Hornsey MJ, Fielding KS. Attitude roots and Jiu Jitsu persuasion: understanding and overcoming the motivated rejection of science. Am Psychol 2017; 72:459-73.

42. Kraft PW, Lodge M, Taber CS. Why people "don't trust the evidence": motivated reasoning and scientific beliefs. Ann Am Acad Pol Soc Sci 2015; 658:121-33.

43. Ward JK, Attwell K, Meyer S, Rokkas P, Leask J. Risk, responsibility and negative responses: a qualitative study of parental trust in childhood vaccinations. J Risk Res 2017; 21:1117-30.

44. Helps C, Leask J, Barclay L, Carter S. Understanding non-vaccinating parents' views to inform and improve clinical encounters: a qualitative study in an Australian community. BMJ Open 2019; 9:e026299.

45. Attwell K, Smith DT, Ward PR. 'The Unhealthy Other': how vaccine rejecting parents construct the vaccinating mainstream. Vaccine 2018; 36:1621-6.

46. Nesse RM. Good reasons for bad feelings: insights from the frontier of evolutionary psychiatry. New York: Dutton; 2019.

47. Sturm LA, Mays RM, Zimet GD. Parental beliefs and decision making about child and adolescent immunization: from polio to sexually transmitted infections. J Dev Behav Pediatr 2005; 26:441-52.

48. Chapman G. A decision-science approach to health-behavior change. Curr Dir Psychol Sci 2019; 28:469-74.

49. Pinker S. Enlightenment now: the case for reason, science, humanism, and progress. New York: Viking; 2018.

50. Omer SB, Salmon DA, Orenstein WA, deHart MP, Halsey N. Vaccine refusal, mandatory immunization, and the risks of vaccine-preventable diseases. N Engl J Med 2009; 360:1981-8.

51. Rose G. Sick individuals and sick populations. Int J Epidemiol 1985; 14:32-8. 


\section{Resumo}

A imunização, a intervenção da saúde pública mais bem sucedida até hoje, só pode ser eficaz se as pessoas elegiveis ou seus representantes legais tiverem acesso às vacinas e aderirem ao seu uso. A subvacinação pode resultar de várias causas: acesso, viabilidade, conscientização, aceitação $e$ ativação. Neste trabalho, focamos na aceitação e, especificamente, nos concentramos nos fatores relativos à cooperação do indivíduo ou de seus pais, especificamente a psicologia do julgamento e da tomada de decisões. Descrevemos como as heurísticas e os vieses cognitivos - um aspecto dos pensamentos e sentimentos - afetam a tomada de decisão quanto à vacinação. Além disso, abordamos quando e como os processos sociais desempenham um papel e como as atitudes em relação às vacinas podem refletir uma atitude ou ideologia subjacente mais geral. A compreensão de como a tomada de decisões em relação às vacinas ocorre e o papel desempenhado pelas heurísticas e pelos vieses cognitivos pode ajudar a informar as intervenções de saúde pública de forma mais adequada.

Vacinação; Cognição; Heurística

\section{Resumen}

La inmunización es la intervención en salud pública más exitosa hasta la fecha. No obstante, sólo puede ser efectiva si las personas elegibles, o sus representantes legales, tienen acceso a las vacunas y, consecuentemente, cumplen con su uso. Existen múltiples causas de infravacunación: acceso, asequibilidad, concienciación, aceptación y activación. En este trabajo, nos enfocamos en la aceptación y esceficamente, centrándonos en factores respecto a la conformidad individual o parental, específicamente en cuanto a la psicología de juicio y toma de decisiones. Describimos como sesgos heurísticos y cognitivos -una faceta de pensamientos y sentimientos- que afectan a la toma de decisiones sobre la vacunación. Asimismo, nos centramos en cuándo y cómo los procesos sociales desempeñan un papel y cómo las actitudes hacia las vacunas quizás reflejen una actitud subyacente más general o ideológica. La compresión sobre cómo se toman las decisiones, en relación a cuándo se tienen que tomar las vacunas y el papel desempeñado por sesgos heurísticos y cognitivos puede informarnos más apropiadamente sobre las intervenciones en salud pública.

Vacunación; Cognición; Heurística

Submitted on 22/May/2020

Approved on 10/Aug/2020 